\title{
Defining language impairments in a subgroup of children with autism spectrum disorder
}

\author{
Helen TAGER-FLUSBERG \\ Department of Psychology, Boston University, Boston MA 02215, USA
}

\begin{abstract}
Autism spectrum disorder (ASD) is diagnosed on the basis of core impairments in pragmatic language skills, which are found across all ages and subtypes. In contrast, there is significant heterogeneity in language phenotypes, ranging from nonverbal to superior linguistic abilities, as defined on standardized tests of vocabulary and grammatical knowledge. The majority of children are verbal but impaired in language, relative to age-matched peers. One hypothesis is that this subgroup has ASD and co-morbid specific language impairment (SLI). An experiment was conducted comparing children with ASD to children with SLI and typically developing controls on aspects of language processing that have been shown to be impaired in children with SLI: repetition of nonsense words. Patterns of performance among the children with ASD and language impairment were similar to those with SLI, and contrasted with the children with ASD and no language impairment and typical controls, providing further evidence for the hypothesis that a subgroup of children with ASD has co-morbid SLI. The findings are discussed in the context of brain imaging studies that have explored the neural bases of language impairment in ASD and SLI, and overlap in the genes associated with elevated risk for these disorders.
\end{abstract}

ASD, SLI, language impairment, comorbidity, brain imaging

Citation: Tager-Flusberg H. Defining language impairments in a subgroup of children with autism spectrum disorder. Sci China Life Sci, 2015, 58: 1044-1052, doi: $10.1007 / \mathrm{s} 11427-012-4297-8$

Core impairments in language and communication are among the defining features of autism spectrum disorder (ASD); here used as an umbrella term for autistic disorder, Asperger syndrome and pervasive developmental disorder-not otherwise specified. Across all these subtypes significant deficits in the ability to use language effectively in a range of social contexts, referred to as pragmatic skills, are evident [1]. These pragmatic impairments are closely tied to impairments in theory of mind, which also underlies deficits in social interaction [2-4]. The majority of children with ASD also have deficits in other aspects of language, including phonological, lexical and grammatical representations, however there is enormous heterogeneity in the language phenotypes associated with ASD, with some children

email: htagerf@bu.edu reaching language milestones (e.g., babbling, age of first words and phrases) on time and having intact linguistic knowledge as measured on standardized language assessments (e.g., many children classified as Asperger syndrome), others remaining nonverbal despite years of intervention, and the majority of children with ASD who are delayed in early language milestones and remain impaired on standardized language tests. From a clinical perspective, these different language phenotypes are important to identify as they lead to very different treatment plans and school placements and the long term prognosis for children with ASD is closely linked to their language abilities (e.g., Billstedt et al. [5]). From a theoretical perspective, these different phenotypes of ASD are significant as they have been associated with different underlying brain structure and organization as well as to language-specific risk genes (e.g., 
Alarcon et al. [6]; de Fossé et al. [7]).

Over the past decade a number of researchers have conducted studies on the subgroups of verbal children with ASD, with particular interest in investigating potential overlap between ASD and specific language impairment (SLI) a developmental language disorder that is defined on the basis of delays and deficits in language without other associated conditions [8]. There are a number of intriguing parallels between these disorders. Both SLI and ASD are complex, highly heritable disorders [9-12] and heterogeneous with respect to severity, prognosis, core symptoms and co-morbidities. A common defining characteristic of ASD and SLI is that they are developmental disorders: diagnosis is based on the emergence of symptoms during the second year of life, but is not usually confirmed until the preschool years, and their phenotypic expression changes over the lifespan (e.g., Conti-Ramsden \& Botting [13]; Howlin et al. [14]). They are conceptualized as behavioral syndromes that are the consequence of genetically influenced altered pathways of neural development affecting the neurocognitive mechanisms associated with language and communication (in the case of ASD, social functioning and restricted behavioral repertoire).

One key question concerns whether these disorders reflect some common underlying deficits in processing linguistic knowledge (e.g., Bishop \& Norbury [15]; Kjelgaard \& Tager-Flusberg [16]; Rapin \& Dunn [17]; Roberts et al. [18]). On standardized language tests verbal children with ASD fall into two subgroups: one whose scores are within the normal range across all subtests, including articulation, vocabulary and higher order syntax and semantics; and a second whose scores are within the normal range for articulation but more than one standard deviation below the mean for vocabulary, and even greater impairments in higher order syntax and semantics [16]. This same pattern has been found for children with SLI [19]. Based on these similar profiles of language impairment on language tests several researchers have proposed that ASD and SLI are partially overlapping neurodevelopmental disorders (e.g., Bishop \& Norbury [15]; Tager-Flusberg [20]). More specifically, autism and language impairment is viewed as a subgroup of ASD with co-morbid SLI. This hypothesis of co-morbidity between these disorders has been challenged by some investigators (e.g., Williams et al. [21]), however, there have been few studies that have gone beyond comparing these groups on standardized language measures, which provide little insight into the mechanisms that underlie linguistic performance.

Two important clinical markers for SLI have been identified for English-speaking children [22]: deficits in grammatical morphology, particularly marking tense in obligatory contexts (e.g., adding -ed for past tense verbs; or -s on third-person singular verbs) and impaired repetition of nonsense words (or 'nonwords'). Impairments in marking tense in children with ASD have been found in several studies using natural language samples. For example, cross-sectional and longitudinal studies, comparing children with ASD to typically developing children, or children with intellectual disability, found that the ASD children are more likely to omit tense morphemes (past and present tense) in obligatory contexts [23-25], a pattern similar to what has been reported in studies of children with SLI (e.g., Rice et al. [26]). More recent investigations have focused on experimental tasks, dividing the ASD group into those with language impairments (referred to here as ALI) and those without (referred to as ALN). Deficits in marking past tense and third person present tense were found in children with ALI and SLI on verb elicitation tasks $[18,27]$. On these elicited production tasks children with SLI and ALI (but not ALN) made more errors than age-matched peers, particularly errors of omission, suggesting similar deficits in underlying language mechanisms (see also Botting \& Conti-Ramsden [28]).

On standardized tests of nonword repetition, children with ALI perform poorly (e.g., Kjelgaard \& Tager-Flusberg [16]; Tager-Flusberg, 2006 [29]), in contrast to the normal performance of children with ALN. Nonword repetition is an important clinical marker of language impairment because it has been linked to the acquisition of more general language skills, including both vocabulary and grammar [30-32] and, unlike tense morphology, it has cross-linguistic validity. It is not known, however, whether problems in nonword repetition involve the same underlying processing deficits in ASD and SLI as no studies have directly compared these groups. Therefore, the goal of this study was to investigate this question by comparing well-matched groups of children in their performance and error patterns on carefully designed experimental tasks of nonword discrimination and repetition.

Extensive research has been conducted on nonword repetition in SLI. Children with SLI perform poorly on nonword repetition tasks, particularly on words with multiple syllables [33-37]. At longer syllable lengths, children make two types of errors: phoneme substitutions and phoneme omissions $[33,38]$. Phoneme substitution errors indicate difficulties in forming or accessing a well-specified phonological representation. Phoneme omission errors indicate a more severe processing difficulty, suggesting that either the phoneme was never stored in phonological short-term memory or the phoneme was stored but could not be maintained or accessed for speech output. Children with and without SLI make more substitution than omission errors, but children with SLI make proportionately more phoneme omissions than children without SLI [38]. Only a few studies have assessed nonword discrimination abilities in SLI using natural speech stimuli. On a same/different discrimination task, children with SLI performed at the same level as agematched controls when discriminating between sets of single syllable real words and nonwords [34]. Montgomery [36] 
included nonword stimuli of 1- to 4-syllable lengths and found that children with SLI made more errors than controls discriminating the longest stimuli, and argued that these findings reflected processing load limitations rather than speech perception deficits. Thus, whether children with SLI have speech perception impairments or limited ability to store phonological information in phonological short-term memory remains unclear. The main purpose of this experiment, therefore, was to investigate whether children with autism (ALI) show the same pattern of performance, including both correct and error responses, as do children with SLI on tasks tapping both nonword discrimination and repetition. Because language impairments in both groups are partly defined with respect to deficits on standardized tests of nonword repetition, the goal was not simply to demonstrate that these groups would perform worse on the experimental tasks, but rather to investigate the patterns of performance to address the key question of whether the same underlying mechanisms might mediate the poorer performance on such tasks.

\section{Method}

\subsection{Participants}

Four groups participated in this study: children with ASD without language impairment (ALN; $N=18 ; 17$ males and 1 female), children with autism and language impairment (ALI; $N=20 ; 17$ males and 3 females), children with SLI ( $N=14 ; 7$ males and 7 females), and typically developing (TD) controls ( $N=21 ; 9$ males and 12 females).

The participants in both ASD groups met DSM-IV criteria for autism [39] based on expert clinical impression and confirmed by the Autistic Diagnostic Interview-Revised (ADI-R [40]) and the Autistic Diagnostic Observation Schedule (ADOS [41]). Participants in the ALI and SLI groups all had a positive clinical history of language delays and deficits, and met the following criteria on standardized testing: a total language score more than 1 standard deviation below the mean on the Clinical Evaluation of Language Fundamentals-III (CELF-III [42]) and/or a score of 6 or below on the Nonword Repetition subtest of the Comprehensive Test of Phonological Processing (CTOPP [43]). The majority of the children in both language impaired groups met current diagnostic criteria on the basis of their nonword repetition scores, reflecting what has been found in other studies of older children with a history of SLI [28,31]. None of the children with SLI met criteria for ASD on either the ADI-R or ADOS and none of the typically developing controls (TD) had symptoms of ASD or language impairment.

The Differential Abilities Scales was used to assess IQ in the participants (DAS [44]). Table 1 presents the descriptive characteristics of the four groups of participants. Using a multivariate ANOVA with group as the independent variable, all four groups were matched on age, $F(3,69)=1.146$, $P=0.337$. The two language-impaired groups, ALI and SLI, were matched on IQ; however, both groups had significantly lower IQ scores than the groups without language impairment (ALN and TD), as is evident by the significant differences between groups on Full Scale IQ, $F(3,69)=$ 11.47, $P<0.01$, Verbal IQ, $F(3,69)=8.42, P<0.01$, and Nonverbal IQ, $F(3,69)=10.49, P<0.01$. The two language impaired groups were also matched on language scores measured by the CELF-III, but their scores were significantly lower than those of participants in the ALN group, $F(2,48)=11.47, P<0.01$.

\subsection{Materials}

A set of 36 nonwords was created that included 9 nonwords for each of 4 stimulus lengths, ranging from 2 to 5 syllables. Nonwords were created based on a modified version of the criteria established by Dollaghan and Campbell [33] so that each stimulus followed English phonotactics and English stress patterns, but were quite unlike any English words (e.g., maufup; vunoitsig; kapoitaevoun; gidzaemauvutab). The nonwords were recorded by a female, native American-English speaker.

The 36 nonwords were randomly assigned to 3 blocks (A, $\mathrm{B}$, and $\mathrm{C}$ ), each block containing 3 nonwords at each of the stimuli lengths (12 words per block). Two blocks were used for the discrimination task and one was used for the repetition task. Each child was presented with all 36 nonwords in blocks A, B, and C, counterbalancing the block assignment across tasks and participants. Thus, across individuals, the same words were used in the discrimination and repetition tasks, ruling out the effect of stimuli as an explanation for

Table 1 Descriptive characteristics of the participants ${ }^{\text {a) }}$

\begin{tabular}{lcccc}
\hline & ALI $(N=20)$ & SLI $(N=14)$ & ALN $(N=18)$ & \multicolumn{1}{c}{ TD $(N=21)$} \\
$M(\mathrm{SD})$ & $M(\mathrm{SD})$ & $10 ;(\mathrm{SD})$ & $11 ; 0(1 ; 9)$ \\
\hline Age & $10 ; 1(2 ; 0)$ & $11 ; 2(2 ; 0)$ & $112.7(18.4)$ & $112.8(14.7)$ \\
Full scale IQ $^{\mathrm{a}}$ & $90.1(14.3)^{* *}$ & $91.1(15.7)^{* *}$ & $103.9(16.4)$ & $111.0(14.2)$ \\
Verbal IQ $^{\mathrm{b}}$ & $88.8(15.2)^{*}$ & $93.5(15.6)^{* *}$ & $115.7(20.5)$ & $111.6(13.5)$ \\
Nonverbal IQ $^{\mathrm{a}}$ & $93.6(15.1)^{* *}$ & $91.0(14.8)^{* *}$ & $110.8(16.9)$ & - \\
CELF-III $^{\mathrm{c}}$ & $95.9(12.8)^{* *}$ & $103.3(9.8)^{*}$ & \\
\hline
\end{tabular}

a) *, $P<0.05$; **, $P<0.01$. a, ALI=SLI $<$ ALN=TD; b, ALI $<$ ALN \& TD and SLI $<$ TD; c, ALI=SLI $<$ ALN. 
performance differences between tasks.

\subsection{Procedure}

\subsubsection{Discrimination task}

The discrimination task was composed of one block of nonwords paired with a matching nonword, and one block in which each nonword was paired with a foil item. The foil item differed from the original nonword by a single consonant changed in either manner, place, or voicing in the initial, medial, or final position of the nonword. The participants completed the discrimination task while sitting in front of a computer monitor with a two-choice button box, labeled "same" and "different". After a brief training with real words, which included corrective feedback, the test stimuli were presented in random order.

\subsubsection{Repetition task}

Children were instructed that they would hear a tone followed by a "made-up" word that did not sound like English, which they were to repeat into the microphone. After a brief training, on which children were given corrective feedback, and when necessary, reminded to listen carefully and speak clearly into the microphone, the 12 test words were presented in random order.

Participants completed the discrimination and repetition tasks in the same testing session, separated by a different activity, with all children receiving the repetition task first.

\subsubsection{Response coding: repetition}

Two trained researchers, blind to the group status of the participants, jointly transcribed the children's responses in broad phonetic transcription and coded following the procedures provided by Dollaghan and Campbell [33].

\subsection{Results}

Preliminary analyses revealed no differences in performance by girls and boys on either task.

\subsubsection{Discrimination}

Table 2 shows the mean number of correct responses for the discrimination task at each stimulus length for each group. A group (ALI, SLI, ALN, TD) by length (2, 3, 4, and 5 syllables) mixed-model repeated measures ANOVA was conducted. There was a significant main effect for length, $F(3$, $207)=15.42, P<0.01$. Post hoc Bonferroni pairwise comparisons $(P<0.01)$ revealed that all groups were significantly less accurate discriminating the 4- and 5-syllable nonwords. There was no significant group effect, $F(3,69)=1.641$, $P=0.188$, or group $x$ length interaction, $F(9,207)=0.669$, $P=0.737$.

To assess whether the position of phoneme contrast affected the children's ability to accurately discriminate between nonwords, the number of correct responses at each phoneme contrast position (initial, medial, and final) was analyzed in a group by position mixed-model ANOVA. A significant main effect was found for position, $F(2,138)=$ 6.43, $P=0.002$. Post hoc Bonferroni pairwise comparisons $(P<0.01)$ indicated that all groups were less accurate at discriminating nonwords when the contrast was in the final position. Again, there was no significant group effect, $F(3$, $69)=1.047, P=0.377$, or group by position interaction, $F(6$, 138) $=0.877, P=0.514$.

\subsubsection{Repetition}

A preliminary inspection of the data showed that performance for all the groups was at floor for the 5-syllable length words, so these were dropped from further analyses.

(i) Total Correct. Table 3 presents the means and standard deviations for the number of correct responses at each stimulus length for the four groups. A group by length mixed-model ANOVA revealed a significant main effect for group, $F(3,69)=11.20, P<0.01$, and length, $F(2,138)=$ 107.25, $P<0.01$. Post-hoc Bonferroni pairwise comparisons $(P<0.01)$ indicated that children in the ALI and SLI groups performed significantly worse than children in the ALN or TD groups and that performance for all groups declined as the nonwords became longer. There was no significant group $x$ length interaction, $F(6,138)=0.767, P=0.597$.

Syllable and phoneme level accuracy. All the children, with the exception of one in the ALN group, repeated the correct number of syllables for every attempted item. Table 4 presents the mean and standard deviations for the percentage of correct phonemes. A group by length mixed-model repeated measures ANOVA found significant main effects for group, $F(3,69)=11.07, P<0.01$, stimulus length, $F(2$, $138)=86.81, P<0.01$, and a significant group by length interaction, $F(6,138)=2.40, P=0.031$. Post hoc Bonferroni pairwise comparisons $(P<0.01)$ indicated that for the 2

Table 2 Mean (and standard deviation) for correct responses on the discrimination task $(\max =6)$

\begin{tabular}{ccccc}
\hline & ALI & SLI & ALN & TD \\
& $M(\mathrm{SD})$ & $M(\mathrm{SD})$ & $M(\mathrm{SD})$ & $M(\mathrm{SD})$ \\
\hline 2 syllables & $4.8(1.1)$ & $5.3(0.9)$ & $5.4(0.6)$ & $5.4(0.6)$ \\
3 syllables & $5.0(0.8)$ & $4.8(1.2)$ & $4.8(0.9)$ & $5.2(0.7)$ \\
4 syllables & $4.4(1.1)$ & $4.2(0.9)$ & $4.5(1.1)$ & $4.7(0.9)$ \\
5 syllables & $4.0(1.1)$ & $4.3(1.1)$ & $4.5(1.0)$ & $4.3(1.0)$ \\
\hline Total & $18.3(2.4)$ & $18.8(2.0)$ & $19.2(2.1)$ & $19.7(1.8)$ \\
\hline
\end{tabular}

Table 3 Mean (and standard deviation) for correct repetitions on the repetition task $(\max =3)$

\begin{tabular}{ccccc}
\hline & ALI & SLI & ALN & TD \\
& $M(\mathrm{SD})$ & $M(\mathrm{SD})$ & $M(\mathrm{SD})$ & $M(\mathrm{SD})$ \\
\hline 2 syllables & $1.8(0.7)$ & $1.7(0.7)$ & $2.5(0.5)$ & $2.2(0.8)$ \\
3 syllables & $0.5(0.7)$ & $0.6(0.5)$ & $1.5(0.8)$ & $1.4(0.8)$ \\
4 syllables & $0.1(0.5)$ & $0.3(0.6)$ & $0.9(0.9)$ & $0.7(0.8)$ \\
\hline Total & $2.5(1.3)$ & $2.7(1.1)$ & $5.0(1.7)$ & $4.3(1.9)$ \\
\hline
\end{tabular}


syllable nonwords the ALI and SLI groups were significantly worse than the ALN group; for the 3 syllable nonwords, these language impaired groups were significantly worse than ALN and TD, and for the 4 syllable nonwords, the ALI group was significantly worse than ALN and TD.

(ii) Error analysis. Table 5 shows the number of substitutions and omissions for the four groups. A preliminary analysis revealed significant negative skewness and kurtosis in the distribution of the data for the number of omission and substitution errors, which could not be normalized with transformations, so non-parametric analyses were conducted. Kruskal Wallis one-way ANOVAs were conducted with group as the independent variable and number of substitutions and number of omission errors as the dependent variables. The groups were significantly different on the number of substitution errors and number of omission errors made, $\chi^{2}=20.69, \mathrm{~d} f=3, P<0.001$, and $\chi^{2}=13.753, \mathrm{~d} f=3, P=0.003$, respectively. Games-Howel Post hoc tests $(P<0.01)$ indicated that the children in the ALI and SLI groups made more substitution errors than the children in the ALN and TD groups. For omission errors, children in the ALI group made significantly more omissions than the children in the TD group; however, even for the ALI group fewer than 2\% of total responses included omission errors.

\section{Discussion}

The main findings from this study confirmed our predictions that children with ALN would perform like TD children, and that ALI children would perform like SLI children on nonword processing tasks. These overall findings underscore the distinction between these subgroups of children with ASD: one without impairments in linguistic processing (ALN) and one with impairments (ALI) that parallel those found in children with SLI. Because correct performance and error patterns across both tasks were similar in the language impaired groups this suggests that the same cognitive mechanisms underlie poor nonword processing in SLI and

Table 4 Percentage of phonemes correct on the repetition task

\begin{tabular}{ccccc}
\hline & ALI & SLI & ALN & TD \\
& $M(\mathrm{SD})$ & $M(\mathrm{SD})$ & $M(\mathrm{SD})$ & $M(\mathrm{SD})$ \\
\hline 2 syllables & $90.0(7.0)$ & $89.5(6.2)$ & $97.0(3.4)$ & $94.6(5.4)$ \\
3 syllables & $82.4(6.7)$ & $79.6(10.6)$ & $89.4(7.4)$ & $91.1(5.3)$ \\
4 syllables & $67.7(12.6)$ & $73.0(15.6)$ & $82.1(14.2)$ & $83.2(8.6)$ \\
\hline Total & $78.0(7.4)$ & $79.1(10.1)$ & $88.1(8.1)$ & $88.6(5.3)$ \\
\hline
\end{tabular}

Table 5 Mean number of substitution and omission errors on the repetition task

\begin{tabular}{ccccc}
\hline & ALI & SLI & ALN & TD \\
& $M(\mathrm{SD})$ & $M(\mathrm{SD})$ & $M(\mathrm{SD})$ & $M(\mathrm{SD})$ \\
\hline Substitution errors & $12.6(4.1)$ & $12.3(5.3)$ & $7.3(4.4)$ & $7.0(3.4)$ \\
Omission errors & $1.2(1.5)$ & $0.8(1.5)$ & $0.3(0.9)$ & $0.2(0.5)$ \\
\hline
\end{tabular}

ALI. Importantly, none of the groups were significantly different from the TD controls on nonword discrimination, indicating relatively intact ability to perceive the speech stimuli and suggesting that deficits that were evident on the production task occur at later stages of phonological processing. On nonword repetition, deficits in the language impaired groups were seen at every syllable length, perhaps because the stimuli used in this study contained no familiar syllable constituents or infrequent phoneme sequences. Errors were made at the phonemic, not the syllable level, with most errors involving substitutions [30,33,38]. Omission errors were rare but more evident in the language impaired children, particularly the ALI group, suggesting that they may have more severe language deficits. Taken together, the findings from this study demonstrate that deficits in nonword repetition in children with SLI and ALI reflect difficulties forming or accessing robust representations of the phonemic characteristics of novel speech sequences. This common underlying cognitive mechanism provides strong evidence for the view that ALI represents a subgroup with ASD and co-morbid SLI.

The fact that the SLI and ALI groups performed poorly on the nonword repetition task was not surprising, especially in light of the fact that the majority of children were diagnosed on the basis of their current deficits on a standardized test tapping the same ability. However, the SLI and ALI children were also distinguished from the TD and ALN group on the basis of their clinical history of enduring delays in language development through the preschool years. Moreover, the major goal of this study was not to document deficits in nonword repetition, but rather to explore the patterns of performance, including error types. It would be important for future studies to compare groups of children with ALI and SLI who are defined on the basis of other measures, not relying as heavily on nonword repetition as did this investigation. Another limitation of the current study is that even though the coders of the repetition task were blind to group status, they may have been able to distinguish the groups on the basis of prosodic differences, which are more common among children with autism [4]. Still, this could not account for the findings as the most striking differences were found between the ALI and ALN groups, both of which would have had prosodic impairments.

In the last part of the discussion, these findings on parallel patterns of language impairment in ASD and SLI will be examined in the broader context of the implications of co-morbidity in considering the neurobiological and genetic bases of these disorders. We begin with what is currently known about the neural bases of language impairment in ASD and SLI, restricting this review to studies using magnetic resonance imaging (MRI). Despite the considerable advances that have been made in recent years, it is important to be cautious about the interpretation of findings from MRI studies. Neurodevelopmental disorders like SLI 
and ASD are known to arise from disturbances in brain development, beginning, perhaps, during early stages of embryonic development. At the same time, a brain image taken from either a child or adult with a disorder is the end product of abnormal brain development, and it is not clear whether observed abnormalities in the image are the cause of behavioral symptoms such as impaired language or the result of the atypical delayed developmental pathway that defines the disorder [45].

Few studies have directly compared these clinical populations using the same methodology, but there are some interesting parallels that have been reported in the literature. In both groups, there are differences in the overall volume and relative volumes of key frontal and temporal lobe language cortical areas in the left and right hemispheres. Some of the findings differ across studies which may be the result of different methods for measuring volumes (e.g., manual versus automated), and different ages of the participants. Using volumetric MRI measures, some investigators found that the right perisylvian regions were larger in children with SLI compared to typical controls [46,47]; in contrast, the left perisylvian regions were either smaller [48,49] or similar in volume [47]. In a quantitative study of anatomic differences in the brains of carefully diagnosed children with SLI and age-matched controls, Gauger and colleagues [50] found that children with SLI had significantly narrower right hemispheres, significantly smaller pars triangularis in the left hemisphere, and greater rightward asymmetry of the total planum, compared to typical controls. However, several more recent studies of boys with SLI carefully matched on age, handedness, and gender to typical controls found greater leftward asymmetry in the planum temporale region $[7,48,51]$.

One striking and replicable finding from neuroimaging studies is that individuals with SLI (e.g., Plante [47]) and ASD (e.g., de Fossé et al. [7]) show atypical asymmetry patterns for language structures and function (for review see Tager-Flusberg et al. [52]). Specifically, both SLI and ASD, particularly those with ALI, show reduced left hemisphere asymmetry in inferior frontal gyral regions (particularly pars opercularis), and exaggerated left asymmetry in posterior planum temporale $[7,48,49,51,53]$; though see Gage et al. [54] for different findings. The volume of left inferior frontal gyral regions is generally reduced in ASD [55] and SLI [50], but the planum continues to show age-related increases in volume through adolescence in ASD based on cross-sectional data [51]. One study [56] investigated white matter in the arcuate fasciculus using diffusion tensor imaging. Fractional anisotropy values were lower in the left hemisphere in children with ALI (compared to controls and ALN) and were correlated with performance on a standardized measure of nonword repetition. This may suggest that performance on nonword repetition requires rapid integration of processing by both frontal and temporal language regions, mediated by the arcuate fasciculus. Functional im- aging studies of language processing using fMRI have found reduced activation in left inferior frontal regions and other areas in both SLI [57] and ASD [58-60], other atypical areas of activation (e.g., cerebellum), and in ASD, reduced functional connectivity between frontal and temporal language areas. Importantly, these atypical activation patterns vary depending on participants' handedness [61]. Taken together, the findings from the neuroimaging literature indicate that language impairments in ASD and SLI are associated with alterations in the volume of key cortical language regions, especially in the left hemisphere, and differences in activation patterns in the network of regions that support language processing. We know little about the developmental origins of these neurobiological differences, but to some extent they are likely to be under genetic control. We also do not know what the functional basis is for nonword repetition tasks and currently there are no published studies that have investigated this using fMRI, however, as with all other language processing tasks it is likely to depend primarily on language regions in frontal and temporal cortex.

There is strong evidence that ASD and SLI are inherited disorders (for reviews see Bespalova \& Buxbaum [62]; Fisher et al. [63]; Folstein \& Rosen-Sheidley [64]) and that there is some overlap evident in families that have a child with these disorders. Family studies of children with ASD and SLI have found that although the majority of firstdegree relatives do not share the same diagnosis, they may have some related features, referred to in the autism literature as the "broader phenotype" $[65,66]$. Lindgren and colleagues [67] found that parents and siblings of children with ASD, particularly those with ALI, had lower language and reading scores compared to controls. Of special interest are the findings that among family members of children with ASD, there are significantly elevated rates of documented histories of language delay and language-based learning deficits [67-71]. These studies suggest that SLI may occur significantly more frequently in families of autistic children than in the general population. There is also evidence that in families identified on the basis of having a child with SLI, there is a significantly elevated risk of autism among the siblings [72].

Language development has a significant genetic component. Behavioral genetic studies with TD twins show that development of grammatical constructions has substantial heritability but little shared environment effects, with higher correlations between abilities of monozygotic twins than dizygotic twins [73,74]. The SLI (Consortium [75,76]; Falcaro et al. [77]) identified two quantitative trait loci in families with SLI: SLI1 locus on $16 \mathrm{q}$ associating with nonword repetition, and SLI2 locus on $19 q$ associating with grammatical impairments. Bishop et al. [78] found that marking tense (verb morphology) does not associate with nonword repetition, but does associate with other grammatical test measures, suggesting $19 q$ may be responsible for all senten- 
tial syntax. Genetic studies of ASD found that linkage signals on were enhanced by including a linguistic endophenotype, specifically, a family history of language-related difficulties [79]. Of greatest interest in current studies are findings by Alarcon and colleagues [6,80] who linked delays in producing first words among boys with ASD to CNTNAP2 (7q35-“contactin associated protein-like 2")a gene in the neurexin family involved in synaptic function. Vernes et al. [81] showed that CNTNAP2 is a downstream target of FOXP2, a transcription factor involved in a human familial speech and language disorder, and that a specific haplotype of CNTNAP2 is associated with nonword repetition in SLI. Finally, it is interesting to note that CATNAP2 shows enriched expression in anterior cortical areas of human fetal brain, including key persylvian language regions [80]. Thus, there is growing evidence that a shared genetic mechanism can be the cause of language impairment across these neurodevelopmental disorders.

Almost all children with ASD show early delays in language milestones. For the majority of these children, language impairments persist over time and can have a significant influence over other aspects of development, such as social cognition and executive functions (e.g., Joseph et al. [82]; Tager-Flusberg \& Joseph [1]). More significantly, language is the single most important predictor of long term functional and adaptive outcomes for this population [5] and is therefore, not surprisingly the key target of early interventions with this population [1]. The study reported here demonstrates that one sensitive, reliable and valid method for detecting language impairment in children and adults with ASD is by using nonword repetition tasks that capture essential features of phonological processing. Nonword repetition taps into core neurocognitive mechanisms that are essential for acquiring and processing language and has been shown to have a strong genetic basis. As such, it serves as an important endophenotype for language impairment for both ASD and SLI and perhaps also for a wider range of neurodevelopment disorders, which may share some of the same genetic and biological risk markers that have been found for ASD (cf. Knaus et al. [61]).

We know little about the early development of language and language-related brain or behavioral processes in infants prior to the onset of ASD symptoms in the second year of life. Future studies should build on what we have already learned about atypical brain organization investigating their origins during the prelinguistic stage in infants at high genetic risk for the disorder. We also know little about the plasticity of these brain and behavioral markers of language impairment though in some recent studies very young children with ASD symptoms appear to have made remarkable progress in catching up in language after delayed onset of key language milestones (e.g., Dawson et al. [83]; Luyster et al. [84]). The ultimate goal will be to provide targeted interventions for at risk infants at an early enough point in development that delays and deficits in language may be pre-empted, thus placing each child on a pathway to mastering the most important human accomplishment-communication with others.

This work was supported by the National Institutes of Health (Grant Nos. U19 DC03610, RO1 DC 10290, and M01 RR00533), General Clinical Research Center Grant and Autism Speaks. I am grateful to Rhyannon Bemis, Karen Condouris, Kelly Ehrman, Lauren Evancie, Brandon Keehn, Lauren McGrath, and Rebecca McNally for their help in collecting, coding and analyzing the data reported here. I offer special thanks to the children and families who participated in this study.

1 Tager-Flusberg H, Joseph RM. How language facilitates the acquisition of false belief understanding in children with autism. In: Why Language Matters for Theory of Mind. Oxford: Oxford University Press, 2005

2 Baron-Cohen S. Social and pragmatic deficits in autism: cognitive or affective? J Autism Dev Disord, 1988, 18: 379-402

3 Happe FG. Current psychological theories of autism: The 'theory of mind' account and rival theories. J Child Psychol Psychiat, 1994, 35: 215-229

4 Tager-Flusberg H. Language and understanding minds: Connections in autism. In: Understanding Other Minds: Perspectives from Developmental Cognitive Neuroscience. Oxford: Oxford University Press, 2000. 124-149

5 Billstedt E, Gillberg IC, Gillberg C. Autism in adults: symptom patterns and early childhood predictors: Use of the disco in a community sample followed from childhood. J Child Psychol Psychiat, 2007, 48: 1102-1110

6 Alarcon M, Cantor RM, Lieu J, Gilliam TC, Geschwind DH, Autism Genetic Research Exchange Consortium. Evidence for a language quantitative trait locus on chromosome $7 \mathrm{q}$ in multiplex autism families. Am J Hum Genet, 2002, 70: 60-71

7 DeFossé L, Hodge SM, Makris N, Kennedy DN, Caviness VS Jr, McGrath L, Steele S, Ziegler DA, Herbert MR, Frazier JA, Tager-Flusberg H, Harris GJ. Language-association cortex asymmetry in autism and specific language impairment. Ann Neurol, 2004, 56: 757-766

8 Rice M L. Specific grammatical limitations in children with specific language impairments. In: Neurodevelopmental Disorders. Cambridge: MIT Press, 1999. 331-359

9 Abrahams BS, Geschwind DH. Advances in autism genetics: on the threshold of a new neurobiology. Nat Rev Genet, 2008, 9: 341-355

10 Choudhury N, Benasich AA. A family aggregation study: The influence of family history and other risk factors on language development. J Speech Lang Hear Res, 2003, 46: 261-272

11 Fisher SE. Dissection of molecular mechanisms underlying speech and language disorders. Appl Psycholing, 2005, 26: 111-128

12 Tomblin JB. Familial concentration of developmental language impairment. J Speech Hear Res, 1989: 287-295

13 Conti-Ramsden G, Botting N. Classification of children with specific language impairment. J Speech Lang Hear Res, 1999, 42: 1195-1204

14 Howlin P, Mawhood L, Rutter M. Autism and developmental receptive language disorder-a follow-up comparison in early adult life. II: Social, behavioural, and psychiatric outcomes. J Child Psychol Psychiat, 2000, 41: 561-578

15 Bishop DVM, Norbury CF. Exploring the borderlands of autistic disorder and specific language impairment: A study using standardized diagnostic instruments. J Child Psychol Psychiat, 2002, 43: 917-929

16 Kjelgaard $\mathrm{M}$, Tager-Flusberg $\mathrm{H}$. An investigation of language impairment in autism: Implications for genetic subgroups. Lang Cogn Proc, 2001, 16: 287-308

17 Rapin I, Dunn M. Update on the language disorders of individuals on the autistic spectrum. Brain Dev, 2003, 25: 166-172

18 Roberts JA, Rice ML, Tager-Flusberg H. Tense marking in children 
with specific language impairment. Appl Psycholing, 2004, 25: 429-448

19 Tomblin JB, Zhang X. Language patterns and etiology in children with specific language impairment. In: Neurodevelopmental Disorders. Cambridge: MIT Press, 1999

20 Tager-Flusberg H. Do autism and Specific Language Impairment Represent Overlapping Language Disorders? Developmental Language Disorders: From Phenotypes to Etiologies. Mahwah: Lawrence Erlbaum Associates, 2004. 31-52

21 Williams D, Botting N, Boucher J. Language in autism and specific language impairment: Where are the links? Psychol Bull, 2008, 134: 944-963

22 Tager-Flusberg H, Cooper J. Present and future possibilities for defining a phenotype for specific language impairment. J Speech Lang Hear Res, 1999, 42: 1275-1278

23 Bartolucci G, Pierce SJ, Streiner D. Cross-sectional studies of grammatical morphemes in autistic and mentally retarded children. J Autism Dev Disord, 1980, 10: 39-50

24 Howlin P. The acquisition of grammatical morphemes in autistic children: a critique and replication of the findings of Bartolucci, Pierce, and Streiner, 1980. J Autism Dev Disord, 1984, 14: 127-136

25 Tager-Flusberg H. A psycholinguistic perspective on language development in the autistic child. In: Autism: New Directions in Diagnosis, Nature and Treatment. New York: Guilford Press, 1989. 92-115

26 Rice ML, Wexler K, Hershberger S. Tense over time: The longitudinal course of tense acquisition in children with specific language impairment. J Speech Hear Res, 1998, 41: 1412-1431

27 Rice ML, Wexler K. Toward tense as a clinical marker of specific language impairment in English-speaking children. J Speech Hear Res, 1996, 39: 1239-1257

28 Botting N, Conti-Ramsden G. Autism, primary pragmatic difficulties and specific language impairment: can we distinguish them using psycholinguistic markers? Dev Med Child Neurol, 2003, 45: 515-545

29 Tager-Flusberg H. Defining language phenotypes in autism. Clin Neurosci Res, 2006, 6: 219-224

30 Gathercole SE, Baddeley AD. Evaluation of the role of phonological STM in the development of vocabulary in children: A longitudinal study. J Mem Lang, 1989, 21: 200-213

31 Montgomery JW. Sentence comprehension in children with specific language impairment: The role of phonological working memory. J Speech Hear Res, 1995a, 38: 187-199

32 Saheln B, Retuerskiold-Wagner C, Nettelbladt U, Radeborg K. Nonword repetition in children with language impairment-pitfalls and possibilities. Int J Lang Commun Disord, 1999, 34: 337-352

33 Dollaghan C, Campbell TF. Nonword repetition and child language impairment. J Speech Lang Hear Res, 1998, 41: 1136-1146

34 Gathercole SE, Baddeley AD. Phonological memory deficits in language disordered children: Is there a causal connection? J Mem Lang, 1990, 29: 336-360

35 Kamhi AG, Catts HW, Mauer D, Apel K, Gentry BF. Phonological and spatial processing abilities in language- and reading-impaired children. J Speech Hear Disord, 1988, 53: 316-327

36 Montgomery JW. Examination of phonological working memory in specifically language-impaired children. Appl Psycholing, 1995b, 16: 355-378

37 Weismer SE, Tomblin JB, Zhang X, Buckwalter P, Chynoweth JG, Jones M. Nonword repetition performance in school-age children with and without language impairment. J Speech Lang Hear Res, 2000, 43: 865-878

38 Edwards J, Lahey M. Nonword repetitions of children with specific language impairment: exploration of some explanations for their inaccuracies. Appl Psycholing, 1998, 19: 279-309

39 Association AP. Diagnostic and Statistical Manual of Mental Disorders (DSM-IV, 4th ed.). Washington, DC: American Psychological Association, 1994

40 Lord C, Rutter M, Le Couteur A. Autism Diagnostic Interview-
Revised: A revised version of a diagnostic interview for caregivers of individuals with possible pervasive developmental disorders. J Autism Dev Disord, 1994, 24: 659-685

41 Lord C, Rutter M, DiLavore PC. Autism Diagnostic Observation Schedule-WPS (ADOS-WPS). Los Angeles: Western Psychological Services, 1999

42 Semel E, Wiig EH, Secord WA. Clinical Evaluation of Language Fundamentals: Examiner's manual. 3rd ed. San Antonio: The Psychological Corporation, 1995

43 Wagner RK, Torgesen JK, Rashotte CA. Comprehensive Test of Phonological Processing (CTOPP): Examiner's manual. Austin: Pro-Ed, 1999

44 Elliott CD. Differential Ability Scales: Administration and Scoring Manual. Orlando: The Psychological Corporation, 1997

45 Muller RA. Genes, language disorders, and developmental archaeology: What role can neuroimaging play? In: Developmental Language Disorders: From Phenotypes to Etiologies. Mahwah: Erlbaum, 2004

46 Filipek P, Richelme C, Kennedy D, Rademacher J, Pitcher DA, Zidel SY, Caviness VS. Morphometric analysis of the brain in developmental language disorders and autism. Ann Neurol, 1992, 32: 475

47 Plante E, Swisher L, Vance R, Rapcsak S. MRI findings in boys with specific language impairment. Brain Lang, 1991, 41: 52-66

48 Herbert MR, Harris GJ, Adrien KT, O'Brien LM, Kennedy DN, Filipek PA, Bakardjiev AI, Hodgson J, Takeoka M, Makris N, Caviness VS Jr. Abnormal asymmetry in language association cortex in autism. Ann Neurol, 2002, 52: 588-596

49 Jernigan TL, Hesselink JR, Sowell E, Tallal PA. Cerebral structure on magnetic resonance imaging in language and learning-impaired children. Arch Neurol, 1991, 48: 539-545

50 Gauger LM, Lombardino LJ, Leonard CM. Brain morphology in children with specific language impairment. J Speech Lang Hear Res, 1997, 40: 1272-1284

51 Knaus TA, Silver AM, Dominick KC, Schuring MD, Shaffer N, Lindgren KA, Joseph RM, Tager-Flusberg H. Age-related changes in the anatomy of language regions in autism spectrum disorder. Brain Imag Behav, 2009, 3: 51-63

52 Tager-Flusberg H, Lindgren K, Mody M. Structural and functional imaging research on language disorders: Specific language impairment and autism spectrum disorders. In: Adult Learning Disorders: Contemporary Issues. New York: Psychology Press, 2008. 127-157

53 Joseph RM, Fricker Z, Fenoglio A, Lindgren KA, Knaus TA, Tager-Flusberg H. Structural asymmetries of language-related gray and white matter as related to language function in young children with ASD. Brain Imaging Behav, 2014, 8: 60-72

54 Gage NM, Filipek PA, Filipek PA, Osann K, Flodman P, Isenberg AL, Spence MA. Rightward hemispheric asymmetries in auditory language cortex in children with autistic disorder: an MRI investigation. J Neurodeve Disord, 2009, 1: 205-214

55 Lindgren K, Dominick K, Knaus T, et al. An MRI study of languagerelated cortices and their relationship to language abilities in ASD and unaffected siblings. under review

56 Lindgren K, Dominick K, Knaus $\mathrm{T}$, et al. A DTI study of language-related white matter in autism spectrum disorder and unaffected siblings. under review

57 Weismer SE, Plante E, Jones M, Tomblin JB. A functional magnetic resonance imaging investigation of verbal working memory in adolescents with specific language impairment. J Speech Lang Hear Res, 2005, 48: 405-425

58 Harris GJ, Chabris CF, Clark J, Urban T, Aharon I, Steele S, McGrath L, Condouris K, Tager-Flusberg H. Brain activation during semantic processing in autism spectrum disorders via functional magnetic resonance imaging. Brain Cogn, 2006, 61: 54-68

59 Just MA, Cherkassky VL, Keller TA, Minshew NJ. Cortical activation and synchronization during sentence comprehension in high-functioning autism: evidence of underconnectivity. Brain, 2004, 
127: $1811-1821$

60 Knaus T, Silver A, Lindgren K, Hadjikhani N, Tager-Flusberg H. fMRI activation during a language task in adolescents with autism spectrum disorder. J Int Neuropsychol Soc, 2008, 14: 967-979

61 Knaus TA, Silver AM, Kennedy M, Lindgren KA, Dominick KC, Siegel J, Tager-Flusberg H. Language laterality in autism spectrum disorder and typical controls: a functional, volumetric, and diffusion tensor MRI study. Brain Lang, 2010, 112: 113-120

62 Bespalova IN, Buxbaum JD. Disease susceptibility genes for autism. Ann Med, 2003, 35: 274-281

63 Fisher SE, Lai CS, Monaco AP. Deciphering the genetic basis of speech and language disorders. Ann Rev Neurosci, 2003, 26: 57-80

64 Folstein SE, Rosen-Sheidley B. Genetics of autism: complex aetiology for a heterogeneous disorder. NatRev Genet, 2001, 2: 943-955

65 Piven J, Palmer P. Psychiatric disorder and the broad autism phenotype: evidence from a family study of multiple-incidence autism families. Am J Psychiatry, 1999, 156: 557-563

66 Tomblin JB, Freese P, Records N. Diagnosing specific language impairment in adults for the purpose of pedigree analysis. J Speech Hear Res, 1992, 35: 832-843

67 Lindgren K, Folstein S, Tomblin JB, Tager-Flusberg H. Language and reading abilities of children with autism spectrum disorders and specific language impairment and their first-degree relatives. Autism Res, 2009, 2: 22-38

68 Bailey A, Palferman S, Heavey L, Le Couteur A. Autism: The phenotype in relatives. J Autism Dev Disord, 1998, 28: 369-392

69 Bolton P, MacDonald H, Pickles A, Rios P, Goode S, Crowson M, Bailey A, Rutter M. A case-control family history study of autism. J Child Psychol Psychiat, 1994, 35: 877-900

70 Folstein SE, Santangelo SL, Gilman SE, Piven J, Landa R, Lainhart J, Hein J, Wzorek M. Predictors of cognitive test patterns in autism families. J Child Psychol Psychiat, 1999, 40: 1117-1128

71 Fombonne E, Bolton P, Prior J, Jordan H, Rutter M. A family study of autism: Cognitive patterns and levels in parents and siblings. J Child Psychol Psychiat, 1997, 38: 667-683

72 Tomblin JB, Hafeman LL, O'Brien M. Autism and autism risk in siblings of children with specific language impairment. Int J Lang Commun Disord, 2003, 38: 235-250

73 Ganger J, Dunn S, Gordon P. Genes take over when the input fails: a twin study of the passive. In: 29th Annual Boston University Conference on Language Development, Boston, USA, 2005
74 Ganger J, Stromswold K. Innateness, evolution, and genetics of language. Hum Biol, 1998, 70: 199-213

75 Consortium S. A genome-wide scan identifies two novel loci involved in specific language impairment (SLI). Am J Hum Genet, 2002, 70: 384-398

76 Consortium S. Highly significant linkage to the SLI1 locus in an expanded sample of individuals affected by specific language impairment. Am J Hum Genet, 2004, 74: 1225-1238

77 Falcaro M, Pickles A, Newbury DF, Addis L, Banfield E, Fisher SE, Monaco AP, Simkin Z, Conti-Ramsden G, SLI Consortium. Genetic and phenotypic effects of phonological short-term memory and grammatical morphology in specific language impairment. Genes Brain Behav, 2008, 7: 393-402

78 Bishop D, Adams C, Norbury C. Distinct genetic influences on grammar and phonological short-term memory deficits: Evidence from 6-year-old twins. Genes Brain Behav, 2006, 5: 158-169

79 Bradford Y, Haines J, Hutcheson H, Gardiner M, Braun T, Sheffield V, Cassavant T, Huang W, Wang K, Vieland V, Folstein S, Santangelo S, Piven J. Incorporating language phenotypes strengthens evidence of linkage to autism. Am J Med Genet, 2001, 105: 539-547

80 Alarcon M, Abrahams B, Stone J, Duvall JA, Perederiy JV, Bomar JM, Sebat J, Wigler M, Martin CL, Ledbetter DH, Nelson SF, Cantor RM, Geschwind DH. Linkage, association, and gene-expression analyses identify CNTNAP2 as an autism-susce- ptivility gene. Am J Hum Genet, 2008, 82: 150-159

81 Vernes SC, Newbury DF, Abrahams BS, Winchester L, Nicod J, Groszer M, Alarcón M, Oliver PL, Davies KE, Geschwind DH, Monaco AP, Fisher SE. A functional genetic link between distinct developmental language disorders. N Engl J Med, 2008, 359: 2337-2345

82 Joseph RM, Steele SD, Meyer E, Tager-Flusberg H. Self-ordered pointing in children with autism: failure to use verbal mediation in the service of working memory? Neuropsychologia, 2005, 43: 1400-1411

83 Dawson G, Rogers S, Munson J, Smith M, Winter J, Greenson J, Donaldson A, Varley J. Randomized, controlled trial of an intervention for toddlers with autism: the Early Start Denver Model. Pediatrics, 2010, 125: 17-23

84 Luyster RJ, Kadlec MB, Carter A, Tager-Flusberg H. Language assessment and development in toddlers with autism spectrum disorders. J Autism Dev Disord, 2008, 38: 1426-1438

Open Access This article is distributed under the terms of the Creative Commons Attribution License which permits any use, distribution, and reproduction in any medium, provided the original author(s) and source are credited. 